\title{
Inverse Association between Fruit and Vegetable Intake and BMI even after Controlling for Demographic, Socioeconomic and Lifestyle Factors
}

\author{
Moonseong Heo ${ }^{\mathrm{a}}$ Ryung S. Kim ${ }^{\mathrm{a}}$ Judith Wylie-Rosett ${ }^{\mathrm{a}}$ David B. Allison ${ }^{\mathrm{b}}$ \\ Steve B. Heymsfield ${ }^{c}$ Myles S. Faith ${ }^{d}$ \\ ${ }^{a}$ Department of Epidemiology and Population Health, Albert Einstein College of Medicine, Bronx, NY, \\ ${ }^{\mathrm{b}}$ Departments of Biostatistics, Nutrition Sciences, Genetics, and Medicine, University of Alabama at Birmingham, Birmingham, AL, \\ ${ }^{c}$ Pennington Biomedical Research Center, Baton Rouge, LA, \\ ${ }^{\mathrm{d}}$ Department of Nutrition, Gillings School of Global Public Health, University of North Carolina at Chapel Hill, Chapel Hill, NC, USA
}

\section{Keywords}

Fruit and vegetable $\cdot$ Obesity $\cdot$ US adults $\cdot$ Health policy . BRFSS

\section{Summary}

Objective: To estimate fruit and vegetable (FV) intake levels of US adult population and evaluate the association between FV intake and BMI status after controlling for confounding demographic, socioeconomic and lifestyle factors. We also sought to identify moderating factors. Methods: We used 2007 Behavior Risk Factors Surveillance System ( $>400,000)$ data. FV intake was dichotomized as $\geq 5$ servings ( $F V 5+$ ) versus $<5$ servings/ day. BMI status was categorized as normal, overweight, and obese. Identification of moderators was performed by testing interactions between BMI status and other variables using bivariate analyses followed by multiple logistic regression analysis incorporating complex survey sampling design features. Results: Only $24.6 \%$ of US adults consumed $\geq 5$ servings per day and less than $4 \%$ consumed 9 or more servings. Overweight (\% FV5+ $=23.9 \%)$ and obese $(21.9 \%)$ groups consumed significantly less FV than the normal-weight (27.4\%) group $(p<0.0001)$. This inverse association remained significant even after controlling for potential confounding factors. Multivariate analysis identified five significant moderators $(p<0.0001)$ after controlling for all evaluated variables: race, sex, smoking status, health coverage, and physical activity. Notably, physically inactive obese males tended to consume the least FV (\% FV5+ $=14.7 \%)$. Conclusion: Current US population FV intake level is below recommended levels. The inverse association between FV intake and obesity was significant and was moderated by demographic, socioeconomic status, and lifestyle factors. These factors should be considered when developing policies and interventions to increase FV intake.

\section{Introduction}

A relatively large intake of fruits and vegetables (FV) is associated with positive general health outcomes such as reduced all-cause mortality and cancer risk [1, 2]. FV intake is also associated with BMI status [3, 4] and a reduced risk of obesityrelated comorbidities such as diabetes [5], cancer problems [6-9], and cardiovascular diseases [10-13]. While these observations often lead to assumed causal relationships, FV intake is also associated with demographic factors [14], socioeconomic status (SES) [15], and lifestyle behaviors [16], collectively referred to as personal status domain (PSD) variables. These PSD variables also are known to be associated with BMI status and health outcomes [17]. Thus, when testing the association between FV intake and adiposity, PSD variables can potentially serve as confounding factors and/or moderators of the FV-BMI status association. Understanding the underlying association between FV intake and BMI status may be advanced by simultaneously modeling these multiple factors.

Although studies have addressed the association of PSD variables with FV intake [18] or obesity [19], we examined

\section{KARGER}

Fax +497614520714

Information@Karger.de

www.karger.com (c) 2011 S. Karger GmbH, Freiburg

$1662-4025 / 11 / 0046-0449 \$ 38.00 / 0$

Accessible online at:

www.karger.com/ofa
Moonseong Heo, $\mathrm{PhD}$

Department of Epidemiology and Population Health

Albert Einstein College of Medicine

1300 Morris Park Avenue, Belfer 1312, Bronx, NY 10461, USA

Tel. +1 718-9206274, Fax -5156029

moonseong.heo@einstein.yu.edu 
whether the extent to which FV-BMI status association is moderated by or the result of confounding from PSD variables at a population level. To this end, we used data from a nationally representative US survey to determine the level of FV intake and associations with PSD variables in the general US adult population. We then assessed the associations between FV intake and BMI with and without controlling for PSD variables. Finally, we identified PSD variables that moderate the FV-BMI status association. As a last stage of our analysis, we explored the characteristics of subject groups with the lowest levels of FV intake.

\section{Material and Methods}

Data from the year 2007 Behavioral Risk Factor Surveillance Survey (BRFSS-07) was used to examine the main study questions. The BRFSS is a US population-based investigation conducted annually since 1984 by the Centers for Disease Control and Prevention (CDC). The BRFSS is the largest ongoing cross-sectional telephone health surveillance survey of the non-institutionalized civilian adult population ages 18 years or older [20]. In 2007, the core questionnaire of the annual survey was administered to 430,912 subjects in all 50 states, the District of Columbia, and two US territories (Puerto Rico and the US Virgin Islands); supplementary modules were administered in various, if not all, selected US states and territories. Responses listed as 'refused' and 'don't know/not sure' were treated as incomplete at the item level; response rates varied across the items. In the present study, we defined FV intake, BMI status, and demographic, socioeconomic and lifestyle behavior variables based on the available BRFSS-07 variables.

\section{Study Outcome}

The CDC calculated daily servings of FV intake based on the following six BRFSS questionnaire items asked by the interviewer, which are transcribed verbatim: 1) 'How often do you drink fruit juices such as orange, grapefruit, or tomato?'; 2) 'Not counting juice, how often do you eat fruit?'; 3) 'How often do you eat green salad?'; 4) 'How often do you eat potatoes not including French fries, fried potatoes, or potato chips?'; 5) 'How often do you eat carrots?'; 6) 'Not counting carrots, potatoes, or salad, how many servings of vegetables do you usually eat? (Example: A serving of vegetables at both lunch and dinner would be two servings). Time frames for FV intake were open to permit the participant to answer using a time frame that could vary from per day for items consumed daily to per year for items consumed very infrequently. The interviewer coded the participant's response for each item as times per day, per week, per month, or per year. All of those responses on different time frames were uniformly converted to the daily servings, i.e., on a per day scale. Detailed computational procedures can be found in 'Calculated Variables in Data Files' available in the BRFSS-07 codebook (www.cdc.gov/brfss/ technical_infodata/surveydata/2007.htm).

The 2005 dietary guidelines from the Department of Health and Human Services (HHS), and the US Department of Agriculture (USDA) 2005 diet guidelines recommended 5-13 FV servings each day for individuals consuming 1,200-3,200 kcal/day [21]. In particular, the guidelines recommended 9 servings per day for an average adult consuming $2,000 \mathrm{kcal} /$ day. However, because the BRFSS investigators were not able to assess participants' daily calorie intake, we used as the primary outcome in this study a dichotomized version of daily FV intake, $\geq 5$ servings (FV5+) versus $<5$ servings/day. Although the 5 servings correspond to the recommendation for the low $1,200 \mathrm{kcal} /$ day intake in the USDA 2005 dietary guidelines, it is consistent with the 5-A-Day recommendation which was initiated in 1991.

\section{Primary Predictor}

BMI status was categorized based on BMI $\left(\mathrm{kg} / \mathrm{m}^{2}\right)$ as normal weight $(18.5 \leq \mathrm{BMI}<25)$, overweight $(25 \leq \mathrm{BMI}<30)$, or obese $(\mathrm{BMI} \geq 30)$. We excluded underweight subjects with a BMI $<18.5$ ( $<2 \%$ of the sample and a group not relevant for comparative purposes in the current study).

\section{Personal Status Domain Variables}

PSD variables consisted of three categories of demographic status, SES, and lifestyle behaviors.

\section{Demographic Variables}

Age (young (18-65 years) vs. old (>65 years)), sex (female vs. male), marital status (married vs. other), and race (non-Hispanic White vs. other).

\section{Socioeconomic Variables}

Education ( $\leq$ high school $(\leq \mathrm{HS})$ vs. college and beyond $(>\mathrm{HS}))$, annual household income ( $<$ USD 35,000 vs. $\geq$ USD 35,000), employment (employed for wages or self-employed vs. other including, out of work, students, homemakers, retirees, and unable to work), and health care coverage (covered by health insurance, prepaid plans such as health maintenance organizations (HMOs), or government plans such as Medicare vs. no coverage).

\section{Lifestyle Behavior Variables}

Smoking status (smoking at least 100 cigarettes in life vs. never smoking) and physical activity with three levels (sufficient physical activity meeting expert recommendations (i.e., either moderate physical activity defined as $30+\mathrm{min} /$ day for $5+$ days/week or vigorous activity for $20+\mathrm{min} /$ day on $3+$ days) vs. insufficient physical activity vs. no physical activity).

Detailed scaling and responses of the PSD variables can also be found in the BRFSS-07 codebook on the above referenced web site.

\section{Data Analysis}

To increase generalizability of the findings to the US adult population and minimize potentially biased point estimates, standard errors, or confidence intervals (CI) due to sampling selections, we incorporated the geographical strata, the primary sampling units (PSU) and the BRFSS-calculated final survey sampling weight into statistical analysis. To this end, we used SAS PROC SRVEYFREQ and SURVEYLOGISTIC procedures. The number of respondents depended on the statistical models across which different sets of questionnaire items were used (i.e., data analyses were conducted based on the available observations per applied statistical method).

Descriptive statistics are presented in terms of $\mathrm{FV} 5+$ prevalence across the considered SES moderators and three BMI status levels. To quantify the association of FV intake with the PSD variables, we used two measures: odds-ratio (OR) and relative difference in $\%=(\%$ in a comparator group $-\%$ in a referent group) / \% in a referent group $\times 100$ [19]. We used the Rao-Scott chi-squared test to test significance of the association of each PSD variables with the FV5+ outcome and computed 95\% $\mathrm{CI}$ for the estimated ORs. We applied survey logistic regressions 1) to test the significance of the FV-BMI status association after controlling for all PSD variables in a single model and 2) to test the significance of potential moderator effects (interaction between each PSD variable and BMI status in the form of FV5+ = BMI status + PSD + BMI status $\times$ PSD, where testing the BMI status $\times$ PSD interaction term was of primary interest.

Finally, to identify significant interaction effects with BMI status controlling for all PSD variables, we applied backward elimination to a full weighted logistic regression analysis with all main and second-order interaction effects with BMI status. In the backward eliminations, all main effects were forced to remain in the model, regardless of their p-value magnitude, in every step. Since the SAS PROC SURVEYLOGISTIC is not able to conduct the backward elimination, we used SAS PROC LOGISTIC with p-values for retention of interaction terms set at a very stringent level of 0.0001 to adjust for the deflated standard errors. 


\section{Results}

At the population level, $24.6 \%$ of US adults consumed FV 5 servings/day or more (fig. 1). Less than $4 \%$ of US adults consumed at least 9 servings of $\mathrm{FV}$, which is the recommended

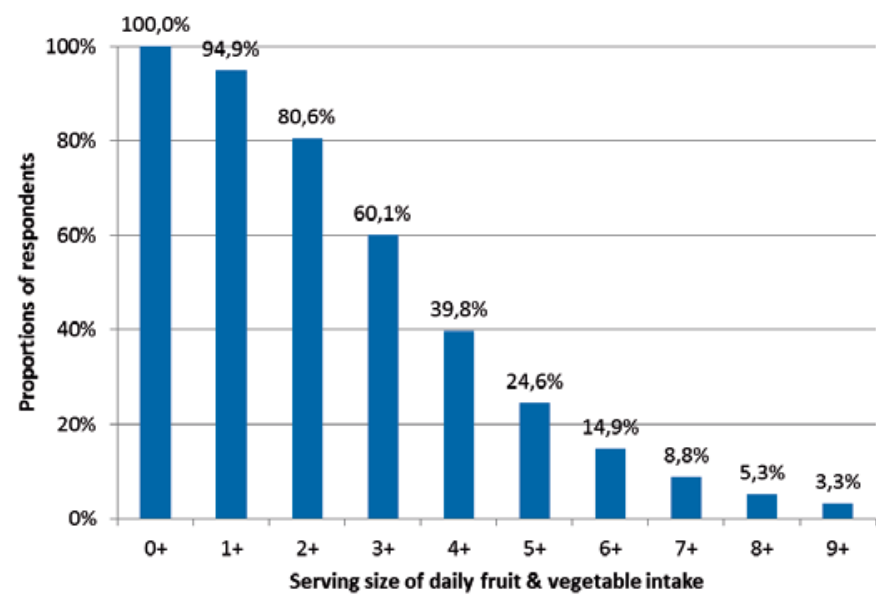

Fig. 1. Reverse cumulative prevalence of serving sizes of daily intake of fruit and vegetables in US adults. Note: $n+$ refers to 'n or more'.
HHS and USDA 2005 Dietary Guideline level. Median FV intake was 3.4 servings/day. The prevalence of FV5+ was significantly associated with BMI status ( $p<0.0001)$ : $27.4 \%$, $23.9 \%$ and $21.9 \%$ for normal-weight, overweight and obese groups, respectively. The crude unadjusted ORs of the overweight and obese groups for FV intake compared to the normal-weight group were $0.83(95 \% \mathrm{CI}=0.80-0.86)$ and 0.74 (95\% CI $=0.71-0.77)$, respectively. Of note, there was little difference in FV5+ prevalence among obese respondents when further categorized into class I $(30 \leq \mathrm{BMI}<35)$, class II $(35 \leq \mathrm{BMI}<40)$ and class III $(\mathrm{BMI} \geq 40)$ groups: $21.8 \%$, $21.6 \%$ and $22.4 \%$, respectively.

Except for race, all other variables were significantly associated with FV5+ $(\mathrm{p}<0.0001)$. In particular, large relative differences of greater than $20 \%$ in FV5+ prevalence were observed for sex, education, smoking status, and physical activity level (table 1). The physically inactive population in particular had the greatest relative difference $(-42.9 \%)$, or the smallest OR (0.50) of FV intake compared to the referent sufficiently physically active group. The current smokers $(\mathrm{OR}=0.63)$, males $(\mathrm{OR}=0.62)$, and subjects with less than college education $(\mathrm{OR}=0.70)$ were also less likely to con-
Table 1. Daily fruit and vegetable intake by demographic status, SES and lifestyle behavior variable

\begin{tabular}{|c|c|c|c|c|c|c|}
\hline Variable & Level & $\mathrm{N}$ & $\%$ FV5+ & $\begin{array}{l}\text { Relative difference, } \\
\% *\end{array}$ & OR & $95 \% \mathrm{CI}$ \\
\hline \multicolumn{7}{|c|}{ Demographic variables } \\
\hline \multirow[t]{2}{*}{ Age } & $18-65$ years & 281,029 & 23.8 & -16.1 & 0.79 & $0.76-0.82$ \\
\hline & $65+$ years (referent) & 112,875 & 28.4 & & & \\
\hline \multirow[t]{2}{*}{ Sex } & male & 153,309 & 20.2 & -30.1 & 0.62 & $0.60-0.64$ \\
\hline & female (referent) & 242,718 & 29.0 & & & \\
\hline \multirow[t]{2}{*}{ Marital } & other & 172,471 & 23.9 & -4.2 & 0.94 & $0.91-0.98$ \\
\hline & married (referent) & 222,587 & 25.0 & & & \\
\hline \multirow[t]{2}{*}{ Race } & non-Hispanic White & 313,889 & 24.5 & -0.6 & $0.99 * *$ & $0.95-1.04$ \\
\hline & other (referent) & 78,809 & 24.7 & & & \\
\hline \multicolumn{7}{|l|}{ SES variables } \\
\hline \multirow[t]{2}{*}{ Education } & $\leq$ high school & 159,746 & 20.7 & -23.6 & 0.70 & $0.68-0.73$ \\
\hline & $>$ high school (referent) & 236,281 & 27.1 & & & \\
\hline \multirow[t]{2}{*}{ Household income } & $<$ USD 35,000 & 140,913 & 22.7 & -11.7 & 0.85 & $0.82-0.88$ \\
\hline & $\geq$ USD 35,000 (referent) & 206779 & 25.7 & & & \\
\hline \multirow[t]{2}{*}{ Employed } & waged/self-employed & 212,485 & 23.3 & -12.4 & 0.84 & $0.81-0.87$ \\
\hline & other (referent) & 182,653 & 26.6 & & & \\
\hline \multirow[t]{2}{*}{ Insurance } & no & 44,144 & 21.7 & -13.7 & 0.83 & $0.78-0.88$ \\
\hline & yes (referent) & 350,972 & 25.1 & & & \\
\hline \multicolumn{7}{|l|}{ Lifestyle variables } \\
\hline \multirow[t]{3}{*}{ Smoking } & current & 72,270 & 18.6 & -30.2 & 0.63 & $0.60-0.66$ \\
\hline & former & 115,786 & 24.7 & -7.3 & 0.90 & $0.87-0.94$ \\
\hline & never (referent) & 206,487 & 26.6 & & & \\
\hline \multirow[t]{3}{*}{ Physical activity } & no activity & 55,919 & 17.9 & -42.9 & 0.50 & $0.55-0.59$ \\
\hline & insufficient & 143325 & 19.9 & -34.4 & 0.57 & $0.47-0.53$ \\
\hline & sufficient (referent) & 177,508 & 30.4 & & & \\
\hline
\end{tabular}

$*$ Relative difference in $\%=($ comparator $\%$ - referent $\%) /$ referent $\% \times 100$.

**Not significant with $\mathrm{p}>0.05$ and all the other ORs are significant.

Note: The lowest prevalence estimate and the largest relative differences are indicated in italics. 
Table 2. FV intake prevalence of $\geq 5$ servings/day (FV5+) by weight status and the PSD variables

\begin{tabular}{|c|c|c|c|c|c|c|c|}
\hline \multirow[t]{2}{*}{ Variable } & \multirow[t]{2}{*}{ Level } & \multicolumn{3}{|l|}{ BMI status, $\%$} & \multirow[t]{2}{*}{ Wald $X^{2 *}$} & \multirow[t]{2}{*}{ df } & \multirow[t]{2}{*}{$\mathrm{p}$ value } \\
\hline & & normal weight & overweight & obese & & & \\
\hline \multicolumn{8}{|c|}{ Demographic variables } \\
\hline \multirow[t]{2}{*}{ Age } & $18-64$ & 26.5 & 23.1 & 21.3 & 1.45 & 2 & 0.485 \\
\hline & $65+$ & 31.8 & 27.1 & 25.3 & & & \\
\hline \multirow[t]{2}{*}{ Sex } & male & 22.6 & 20.1 & 18.1 & 3.60 & 2 & 0.165 \\
\hline & female & 30.7 & 29.2 & 25.8 & & & \\
\hline \multirow[t]{2}{*}{ Marital } & other & 25.4 & 23.8 & 22.0 & 25.50 & 2 & $<0.001$ \\
\hline & married & 29.0 & 23.9 & 21.8 & & & \\
\hline \multirow[t]{2}{*}{ Race } & non-Hispanic White* & 27.9 & 23.5 & 21.2 & 15.86 & 2 & $<0.001$ \\
\hline & other & 26.1 & 24.7 & 23.1 & & & \\
\hline \multicolumn{8}{|l|}{ SES variables } \\
\hline \multirow[t]{2}{*}{ Education } & $\leq$ high school & 22.1 & 20.7 & 19.3 & 15.56 & 2 & $<0.001$ \\
\hline & > high school & 30.4 & 25.9 & 23.9 & & & \\
\hline \multirow[t]{2}{*}{ Household income } & $<\operatorname{USD} 35,000$ & 24.7 & 22.8 & 20.5 & 10.90 & 2 & 0.004 \\
\hline & $\geq$ USD 35,000 & 29.3 & 24.3 & 22.8 & & & \\
\hline \multirow[t]{2}{*}{ Employed } & waged/self-employed & 26.2 & 22.4 & 21.1 & 6.44 & 2 & 0.040 \\
\hline & other & 29.2 & 26.5 & 23.2 & & & \\
\hline \multirow[t]{2}{*}{ Insurance } & no & 22.9 & 22.6 & 19.0 & 8.04 & 2 & 0.018 \\
\hline & yes & 28.2 & 24.1 & 22.4 & & & \\
\hline \multicolumn{8}{|l|}{ Lifestyle variables } \\
\hline \multirow[t]{3}{*}{ Smoking } & current & 19.9 & 17.9 & 17.81 & 14.79 & 2 & 0.005 \\
\hline & former & 28.9 & 23.8 & 21.7 & & & \\
\hline & never & 29.5 & 25.9 & 23.4 & & & \\
\hline \multirow[t]{3}{*}{ Physical activity } & no activity & 18.8 & 18.2 & 16.9 & 10.99 & 4 & 0.027 \\
\hline & insufficient & 21.7 & 19.2 & 19.1 & & & \\
\hline & sufficient & 33.2 & 29.1 & 27.3 & & & \\
\hline
\end{tabular}

*The test statistics for the interaction terms (BMI status $\times$ PSD) are based on the application SAS PROC SURVEY LOGISTIC to the models in the form of FV5+ = BMI status + PSD + BMI status $\times$ PSD, where the BMI status term was represented by two dummy variables.

Note: The lowest prevalence estimates are indicated in italics. sume FV compared to their counterparts. Even after controlling for all PSD variables in a single logistic regression model, both the overweight (adjusted $\mathrm{OR}=0.92,95 \% \mathrm{CI}=0.88$ 0.96 ) and obese (adjusted $\mathrm{OR}=0.86,95 \% \mathrm{CI}=0.82-0.91$ ) groups consumed significantly less FV compared to the normal-weight group.

Results from bivariate moderator analyses are presented in table 2. Although age was significantly associated with FV intake, it did not significantly moderate the association between BMI status and FV intake. On the other hand, the interaction effect between race and BMI status on FV intake was significant even though race was not significantly associated with FV intake. For example, the OR of the obese versus the normal-weight group for FV intake is much lower in the nonHispanic White group $(\mathrm{OR}=0.70)$ compared to that in the other race groups $(\mathrm{OR}=0.85)$, a $22.3 \%$ change in $\mathrm{OR}$. Interaction effects of all other PSD variables with weight status on FV intake were highly significant.

The backward elimination with all main effects forced to remain in each step resulted in the following variables whose interactions with BMI status had significant effects at $\mathrm{p}<0.0001$ on FV: sex, smoking status, race, health insurance coverage, and physical activity. Finally, observing that both sex and physical activity levels had strong main (table 1) and interaction effects from the backward elimination on FV intake, we further sub-grouped FV5+ prevalence by sex and physical activity levels (fig. 2). As shown in the figure, only $14-15 \%$ of males with no physical activity consumed FV more than 5 times/day regardless of their BMI status, a prevalence about $10 \%$ lower than that of the overall population. The physically inactive group in particular had the lowest prevalence of FV5+ for normal and obese weight status, with the lowest FV intake in the obese subjects $(17.9 \%)$. The low prevalence was even more pronounced for physically inactive obese males among whom the prevalence was as low as $14.7 \%$, which was about the half of that of the normal-weight general population. This prevalence was lower than that of obese male current smokers was $16.5 \%$. On the other hand, $37 \%$ of females with sufficient physical activity levels consumed $>5 \mathrm{FV}$ per day. 

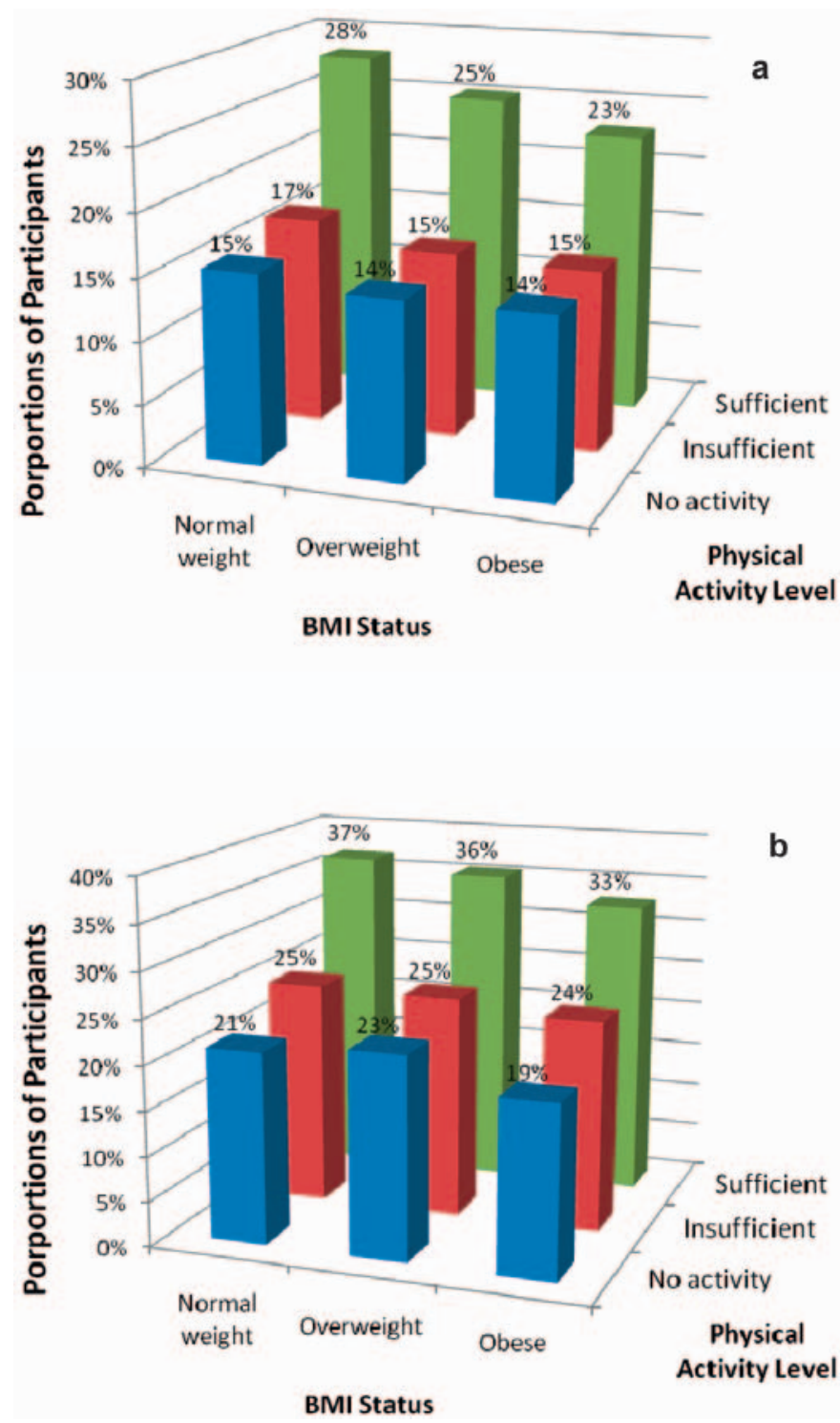

Fig. 2. a Prevalence of FV intake more than five servings per day by BMI status and physical activity levels in males. b Prevalence of FV intake more than 5 servings per day by BMI status and physical activity levels in females.

\section{Discussion}

The principal findings from this study are that FV intake of the US adult population is inadequate according to recommendations from the federal government and significantly lower among overweight and obese compared to the normalweight individuals. Although the FV-BMI status association was attenuated after controlling for the PSD variables, the adjusted association remained significant. Therefore, the significant inverse association between BMI status and FV intake is not necessarily a spurious finding due to potential confounding factors that are significantly associated with both BMI status and FV intake. Only a quarter of the population meets the 2005 Dietary Guidelines recommended minimum intake of $5 \mathrm{FV}$ servings per day. Furthermore, less than $4 \%$ of respondents consumed at least 9 servings of FV per day, the recommendation for an energy intake of 2,000 kcal/day.

These findings regarding low FV intake in overweight and obese adults may have important public health implications. Population weight management could conceivably be enhanced by increased intake of FV [22]. Low FV intake level was significantly associated with each of the demographic, SES and lifestyle variables. Notably, FV intake was lower in individuals who were male, lower in SES indices, current smokers, and physically inactive. Reduced FV intake in the low income group may reflect the higher cost of nutrientdense foods including fruits and vegetables [23]. Nevertheless, the employed participants consumed less FV than other groups. Although, the underlying reasons for this finding are unknown, provision of FV as snacks at workplaces might increase FV intake for the employed groups. The FV intake of former smokers is comparable to that of the general population (table 1). It is unknown however whether smoking cessation might have induced higher FV intake (compared to the current smokers) to reduce potential weight gains [24]. After all, as shown in the results section, the low FV intake in the obese group is even poorer when combined with lower indices of SES, smoking status, and physical inactivity (table 2).

Taken together, our findings suggest that various public health strategies to reduce obesity by recommending increased physical activity and a healthy diet might have not been sufficiently effective to meet goals, despite the prominent 5-A-Day national campaign initiated in 1991 [25]. Whether this reflects a limitation in the design of such programs, their implementation, their efficacy in promoting FV consumption, or the efficacy of FV consumption in reducing obesity is unclear. One plausible factor might be insufficient effort in building (or eliminating) environments that can promote (or diminish) both physical activity and FV intake at the personal and public levels [26-28]. Given the significant medical complications of obesity, more effective environmental modifications to promote easier access to places for physical activities, increase in local FV markets, and enhanced neighborhood safety are being broadly considered [29] and in parallel with government policy and programs [30]. The 2008 Farm Bill provisions, in particular, have increased the availability of FV in USDA initiatives such as school food service, Women's Infants and Children's (WIC) program, and Food Stamp Program, the latter of which has been renamed as Secured Supplemental Nutrition Assistance Program (SSNAP) providing financial incentives toward promotion of $\mathrm{FV}$ purchases.

Taxation on high calorie-dense foods and beverages in conjunction with efforts to increase the difficulty in their access is also being considered by some as a part of policy and environmental modifications [31]. Broader health insurance coverage, which remains as a significant moderator in the multivariate backward elimination, could also be conjectured to be helpful since increased utilization of health care services might in- 
crease awareness of the benefits of a healthy diet, physical activity, and weight loss. When implemented, these policies and programs might effectively enhance physical activity and FV intake and reduce obesity prevalence with greater sustainability, compared to information dissemination alone. In addition, sustained implementation of innovative interventions could also plausibly aid in reducing the population BMI through an increase in FV intake [32]. For example, family-based studies have suggested that interventions targeting increased FV intake may be as effective those targeting reduced high-fat/ high-sugar foods for childhood obesity prevention [33, 34].

The interpretation and implication of the present study findings should be made in the context of several limitations. First, all data were obtained by self-report, which is subject to bias and potential underestimation of BMI [31]. The BRFSS07 underestimated BMI [35], though not sizeable, when compared to NHANES 1999-2004 measured prevalence [36]. Nevertheless, the FV consumption items were previously reported to have moderate reliability and validity [37]. Furthermore, a recent study showed that self-report BRFSS responses are highly correlated with objectively measured constructs such as human well-being [38]. Second, actual FV serving portion size consumed by respondents is unknown. The questions in the BRFSS-07 were based on an implicit assumption of one serving being equivalent to a half cup, which can affect the validity of the reported FV servings, although the FV intake items were previously reported to have moderate reliability and validity [37]. Another limitation concerns missing data. Subjects without complete information about the PSD variables subjects $(\mathrm{N}=327,931)$ consisted of $24 \%$ of the respondents. However, the prevalence of FV5+ among these subjects was not substantively affected, with an estimate of $24.8 \%$. Likewise, the prevalence across BMI status groups re- mained little affected with estimates of $27.9 \%, 23.9 \%$ and $22.0 \%$ in the normal-weight, overweight and obese groups, respectively. Furthermore, the multivariate analyses were based on the subjects with complete information. Finally, persons without telephone service, those in institutions or those in the military, were not included in the BRFSS.

In conclusion, US adults in general consumed much fewer servings of FV than recommended by the USDA 2005 guidelines: $24.6 \%$ of adults consumed FV 5 times or more per day, and less than $4 \%$ consumed 9 servings/day or more. Obesity, SES, and physical activity are associated with poor FV intake, a fact which may merit consideration when developing policies and interventions to increase FV intake. Finally, future studies should examine whether the FV-BMI status associations are also applicable to the general pediatric and adolescent populations.

\section{Acknowledgements}

Dr. Allison has received grants, contracts, consulting fees, honoraria, royalties, and donations from numerous not-for-profit and for-profit entities with interests in obesity and food intake including but not limited to food companies, restaurant companies, and commodity, restaurant, and food manufacturer trade associations. Dr. Faith has held several NIH grants to study family-based treatments for childhood obesity which included prescriptions to increase fruit and vegetable intake. This study was supported in part by the NIH grant 5R18DK07981 to Judy WylieRosett.

\section{Disclosure Statement}

The other authors have none to disclose.

\section{References}

1 Kant AK: Dietary patterns and health outcomes. J Am Diet Assoc 2004;104:615-635.

2 Van Duyn MS, Pivonka E: Overview of the health benefits of fruit and vegetable consumption for the dietetics professional: selected literature. J Am Diet Assoc 2000;100:1511-1521.

3 Ledikwe JH, Blanck HM, Khan LK, Serdula MK, Seymour JD, Tohill BC, Rolls BJ: Dietary energy density is associated with energy intake and weight status in us adults. Am J Clin Nutr 2006;83:13621368.

4 Tohill BC, Seymour J, Serdula M, Kettel-Khan L, Rolls BJ: What epidemiologic studies tell us about the relationship between fruit and vegetable consumption and body weight. Nutr Rev 2004;62:365-374.

5 Ford ES, Mokdad AH: Fruit and vegetable consumption and diabetes mellitus incidence among us adults. Prev Med 2001;32:33-39.

6 Rock CL, Demark-Waknefried W: Nutrition and survival after the diagnosis of breast cancer: a review of the evidence. J Clin Oncol 2002;20:3302-3316.
7 Steinmetz KA, Potter JD: Vegetables, fruit, and cancer prevention:a review. J Am Diet Assoc 1996; 96:1027-1039.

8 World Cancer Research Fund/American Institute for Cancer Research: Food, Nutrition, Physical Activity, and the Prevention of Cancer: A Global Perspective. Washington DC, ACIR, 2007.

$\checkmark 9$ Calle EE, Kaaks R: Overweight, obesity and cancer: epidemiological evidence and proposed mechanisms. Nat Rev Cancer 2004;4:579-591.

10 Rimm EB, Ascherio A, Giovannucci E, Spiegelman D, Stampfer MJ, Willett WC: Vegetable, fruit, and cereal fiber intake and risk of coronary heart disease among men. JAMA 1996;275:447-451.

11 Ignarro LJ, Balestrieri ML, Napoli C: Nutrition, physical activity, and cardiovascular disease: an update. Cardiovasc Res 2007;73:326-340.

12 Hung HC, Joshipura KJ, Jiang R, Hu FB, Hunter D, Smith-Warner SA, Colditz GA, Rosner B, Spiegelman D, Willett WC: Fruit and vegetable intake and risk of major chronic disease. J Natl Cancer Inst 2004;96:1577-1584.
13 Lavie CJ, Milani RV, Ventura HO: Obesity and cardiovascular disease risk factor, paradox, and impact of weight loss. J Am Coll Cardiol 2009;53: 1925-1932.

14 Subar AF, Heimendinger J, Patterson BH, Krebssmith SM, Pivonka E, Kessler R: Fruit and vegetable intake in the united states - the baseline survey of the 5-A-Day for Better Health Program. Am J Health Promot 1995;9:352-360.

15 James WPT, Nelson M, Ralph A, Leather S: Socioeconomic determinants of health - the contribution of nutrition to inequalities in health. Br Med J 1997;314:1545-1549.

16 Whichelow MJ, Prevost AT: Dietary patterns and their associations with demographic, lifestyle and health variables in a random sample of british adults. Br J Nutr 1996;76:17-30.

17 Giskes K, van Lenthe FJ, Turrell G, Kamphuis CBM, Brug J, Mackenbach JP: Socioeconomic position at different stages of the life course and its influence on body weight and weight gain in adulthood: A longitudinal study with 13-year follow-up. Obesity (Silver Spring) 2008;16:1377-1381. 
18 Darmon N, Drewnowski A: Does social class predict diet quality? Am J Clin Nutr 2008;87:1107-1117.

19 Giskes K, Avendano M, Brug J, Kunst AE: A systematic review of studies on socioeconomic inequalities in dietary intakes associated with weight gain and overweight/obesity conducted among european adults. Obes Rev 2010;11:413-429.

20 Centers for Disease Control and Prevention (CDC): Behavioral Risk Factor Surveillance System Survey Data. Atlanta, Centers for Disease Control and Prevention, 2007.

21 U.S. Department of Health and Human Services and U.S. Department of Agriculture: Dietary Guidelines for Americans, 2005, 6th ed. Washington, DC, Goverment Printing Office, 2005.

-22 He K, Hu FB, Colditz GA, Manson JE, Willett WC, Liu S: Changes in intake of fruits and vegetables in relation to risk of obesity and weight gain among middle-aged women. Int J Obes 2004;28: 1569-1574.

23 Drewnowski A, Specter SE: Poverty and obesity: the role of energy density and energy costs. Am J Clin Nutr 2004;79:6-16.

-24 Buijsse B, Feskens EJM, Schulze MB, Forouhi NG, Wareham NJ, Sharp S, Palli D, Tognon G, Halkjaer J, Tjonneland A, Jakobsen MU, Overvad K, van der A DL, Du HD, Sørensen TIA, Boeing $\mathrm{H}$ : Fruit and vegetable intakes and subsequent changes in body weight in European populations: results from the project on diet, obesity, and genes (diogenes). Am J Clin Nutr 2009;90:202-209.

$\checkmark 25$ Casagrande SS, Wang Y, Anderson C, Gary TL: Have Americans increased their fruit and vegetable intake? The trends between 1988 and 2002. Am J Prev Med 2007;32:257-263.

26 Story M, Kaphingst KM, Robinson-O'Brien R, Glanz K: Creating healthy food and eating environments: policy and environmental approaches. Annu Rev Public Health 2008;29:253-272.

27 Sloane DC, Diamant AL, Lewis LB, Yancey AK, Flynn G, Nascimento LM, McCarthy WJ, Guinyard JJ, Cousineau MR, Build RCAA: Improving the nutritional resource environment for healthy living through community-based participatory research. J Gen Intern Med 2003;18:568-575.

28 Glanz K, Yaroch AL: Strategies for increasing fruit and vegetable intake in grocery stores and communities: policy, pricing, and environmental change. Prev Med 2004;39(suppl 2):S75-S80.

-29 Lovasi GS, Hutson MA, Guerra M, Neckerman KM: Built environments and obesity in disadvantaged populations. Epidemiol Rev 2009;31:7-20.

30 McKinnon RA, Orleans T, Kumanyika SK, Haire-Joshu D, Krebs-Smith SM, Finkelstein EA, Brownell KD, Thompson JW, Ballard-Barbash R: Considerations for an obesity policy research agenda. Am J Prev Med 2009;36:351-357.

31 Lichtman SW, Pisarska K, Berman ER, Pestone M, Dowling H, Offenbacher E, Weisel H, Heshka S, Matthews DE, Heymsfield SB: Discrepancy between self-reported and actual caloric-intake and exercise in obese subjects. N Engl J Med 1992;327: 1893-1898.

32 Pomerleau J, Lock K, Knai C, McKee M: Interventions designed to increase adult fruit and vegetable intake can be effective: a systematic review of the literature. J Nutr 2005;135:2486-2495.

-33 Epstein LH, Gordy CC, Raynor HA, Beddome M, Kilanowski CK, Paluch R: Increasing fruit and vegetable intake and decreasing fat and sugar intake in families at risk for childhood obesity. Obes Res 2001;9:171-178.
34 Epstein LH, Paluch RA, Beecher MD, Roemmich JN: Increasing healthy eating vs. reducing high energy-dense foods to treat pediatric obesity. Obesity (Silver Spring) 2008;16:318-326.

35 Heo M, Pietrobelli A, Wang D, Heymsfield SB, Faith MS: Obesity and functional impairment: influence of comorbidity, joint pain, and mental health. Obesity (Silver Spring) 2010;18:2030-2038.

36 Ogden CL, Carroll MD, Curtin LR, McDowell MA, Tabak CJ, Flegal KM: Prevalence of overweight and obesity in the united states, 1999-2004. JAMA 2006;295:1549-1555.

37 Nelson DE, Holtzman D, Bolen J, Stanwyck CA, Mack KA: Reliability and validity of measures from the behavioral risk factor surveillance system (BRFSS). Soz Praventivmed 2001;46(suppl 1):S3-42.

38 Oswald AJ, Wu S: Objective confirmation of subjective measures of human well-being: evidence from the USA. Science 2010;327:576-579. 